\title{
The Influence of Harmful Substances on the Pigments of Leaves of Decorative Trees
}

\author{
Halmatov Musliddin Muhammatovich ${ }^{1^{*}}$, \\ Ismoilxodjayev Bokhodixodja Sharibxodjaevich ${ }^{1}$, \\ Sulaymonov Sharifjon Abdumanabovich ${ }^{1}$ \\ and Latibov Shohruhbek Mahamatyusup ${ }^{1}$ \\ ${ }^{1}$ Andijan Institute of Machine Technology, Uzbekistan.
}

Authors' contributions

This work was carried out in collaboration among all authors. Author HMM performed the statistical analysis, wrote the protocol and wrote the first draft of the manuscript in native language. Author IBS managed the analyses of the study. Author SSA managed the literature searches. Author LSM designed the study. All authors read and approved the final manuscript.

Article Information

DOI: 10.9734/ARRB/2019/v33i430130 Editor(s):

(1) Dr. Msafiri Yusuph Mkonda, Lecturer, Sokoine University of Agriculture, Tanzania. Reviewers:

(1) Atilla Akbaba, Izmir Katip Celebi University, Turkey.

(2) Chadetrik Rout, Maharishi Markandeshwar (Deemed to be University), India. Complete Peer review History: https://sdiarticle4.com/review-history/52518

Original Research Article

Received 26 August 2019

Accepted 01 November 2019

Published 08 November 2019

\section{ABSTRACT}

Republic of Uzbekistan the composition of the atmospheric air on the main streets, the level of traffic on these streets, the selection of resistant species of phenol trees for growing ornamental trees, and the laws of changing the amount of pigments in these trees depending on the streets and season. At the same time, the types of ornamental trees and their resistance to pollution from the pollution of carbon dioxide, nitrogen oxides and sulfur dioxide are mainly represented by atmospheric air pollution.

Keywords: Trees; leaves; assortment; leaf pigments; chlorophyll "a" chlorophyll "b".

\section{INTRODUCTION}

Nowadays the growth rate of large cities depends on the growth of industrial enterprises and motor transport, which requires many environmental issues. Air pollution is mainly caused by large-scale enterprises and motor vehicle emissions, especially on roads along 
major highways, with motor vehicle emissions. In this case, pollutants are mainly exposed to tree leaves. This is because the photosynthesis and many other processes that allow the growth of the leaves to take place in these leaves. There fore, it is important to study the degree of contamination of tree leaves with various contaminants and to evaluate the resistance of these toxic compounds to the green and yellow pigments involved in the photosynthesis process in the leaves and their resistance to heavy metals.

The volumes of carbon dioxide absorption and oxygen production in different species of trees and leaves vary. The air purification efficiency of ordinary juniper trees is $100 \%$, pine - $164 \%$, large deciduous - $254 \%$, oak - $450 \%$ and Berlin poplar - 691\% [1]. Decorative trees play not only an aesthetic and social role for the environment, but also affect the quality of atmospheric air [2]. Trees in urban areas were planted in order to create favorable environmental conditions close to optimal parameters corresponding to the socalled comfort zone. When the wind speed in the comfort zone is $2-6 \mathrm{~m} / \mathrm{s}$ and the relative speed is $30-70 \%$, then the average temperature is about $18-28^{\circ} \mathrm{C}$. Under favorable conditions, the noise should not exceed $45 \mathrm{~dB}$ (in the evening) and $65 \mathrm{~dB}$ (in the afternoon). Keep in mind that comfort conditions are determined by a number of factors and depend on the degree of air pollution with gases and other particles [3]. In nature, there are also artificial forests, parks, and even single trees, which have a significant impact on improving the climate, creating a high level of comfort and hygiene. The green massif has its own microclimate [4]. According to Roberta Baroni Fornasiero, fluoride and many fluorides are vital to humans and plants. Fluoride flora is found in highly industrial areas: characteristic leaves are present on the leaves, the tip of which separates them from burns and healthy, undamaged tissues. As a result of pollution, it is observed that the leaves of the trees fall, the ends and edges of the leaves change and they turn red and brown [5]. Air pollutants are any gases or solid particles that can be harmful to human health and the environment at a sufficiently high concentration. It is known that air pollution occurs mainly by two sources: natural factors and a human product from anthropogenic sources, or both. Pollutants are found in most parts of the troposphere; nevertheless, surface pollution in the boundary layer is the most alarming, since the concentrations caused by surface sources are relatively high [6]. An increase in population, a reduction in natural resources, an increase in pollutants enhances climate change. It was previously believed that the climate does not affect the surface of the earth or living organisms in the earth's crust. Currently, it plays an important role in determining climate change on Earth [7]. Currently, global warming associated with climate change is one of the most discussed topics. There are also natural causes in addition to the various anthropogenic effects of air pollution around the world. Many factors play a decisive role in the process of climate change and global warming, which leads to changes in global temperatures and the nature of precipitation [8]. Anthropogenic pollution occurs mainly due to pollutants entering the air from industrial enterprises, automobile, air, rail, water transport and the use of various types of fuel. In the era of science and technology, air pollution is becoming more intense [9]. Currently, there are more than 40,000 sources of air pollution in Uzbekistan, and almost half of them are not equipped with filters, which leads to more than 2 million pollutants in the country with more than 150 pollutants per year, tons of waste are released into the atmosphere [10]. As a result of the effect of polluted air on the environment, many health problems arise both for the environment and for humans and cause diseases such as asthma, bronchitis, cardiovascular diseases, heart attack and hypertension [11]. The largest industrial cities of the country are Tashkent, Andijan, Fergana, Navoi and others, which are among the largest cities in Europe in terms of air pollution [12]. Atmospheric air is mainly contaminated with carbon monoxide, nitrogen oxides and sulfur oxides. From a scientific point of view, the choice of decorative trees and their durability is important for cleaning and protecting the air from pollution. In this situation, it is necessary to conduct phenological observations of growing trees under these conditions and study the quantity and quality of substances in their various organs. It is also known that most of the toxins are primarily affected by the leaves of the trees due to photosynthesis and many processes that occur in them. From this we can conclude that the amount of photosynthetic pigments in trees is a measure of resistance to harmful gases in trees. Given the above, we plan to study the formation of green and yellow dyes on the leaves on the example of the city of Andijan. Purpose of the study. Study of drought tolerance of decorative trees, determination of atmospheric air pollution, seasonal studies of dyes in tree 
leaves along the main highways of the city of Andijan.

\subsection{The Purpose of the Study}

The study of the drought resistance of ornamental trees at the level of pollution caused by atmospheric air on the basis of seasonal study of dyes in the leaf of trees along the major highways of Andijan with industrial development and high traffic.

\subsection{Scientific Novelty}

For the first time the Republic of Uzbekistan the study of the influence of pollutants on atmospheric air in the Andizhan region on the viability of ornamental trees, the synthesis of pigments on the leaves and heavy metals.

\section{RESEARCH METHODS}

Each leaf was diluted to 50 milligrams to determine the amount of chlorophyll "a", chlorophyll "b" and carotenoids in plant leaves. Each leaf specimen was homogenized in 5 to $100 \%$ acetone solution. The homogenate was centrifuged at $10,000 \mathrm{mph}$ at a rate of 5,000 . Chlorophyll "a", chlorophyll "b" and carotenoid light absorption values were determined at 662, 645 and $470 \mathrm{~nm}$ (Agilent Cary 60 UV-Vis spectrophotometer). On the basis of this index, chlorophyll "a", chlorophyll "b" and carotenoid content in leaves of ornamental trees were calculated using the equation Lichtentaler and Wellburn (1985):
Statistical analysis of experimentally obtained plant chlorophyll a and chlorophyll b and caratinoid levels was performed in EXSEL 2016, Stat View 5.0 by anova.

\section{RESULTS AND DISCUSSION}

It was found that the amount of pigments in tree leaves also varied depending on the amount of pollutants in the air. For example, A. Chlorophyll in oak and juniper trees grew on Temur Street $(3,845 ; 1,163 \mathrm{mg} / \mathrm{g})$ and, on the contrary, the chlorophyll content in leaves of these trees growing on Bobur Avenue was minimal. (3,016; $0.845 \mathrm{mg} \mathrm{/} \mathrm{g)} \mathrm{It} \mathrm{should}$ be noted that the chlorophyll content in the juniper tree grown on A. Temur Street is almost the same as the control chlorophyll in the tree leaves. This is due to the fact that this level of pollution has little impact on fir tree.

Chlorophyll in chestnut leaves grown in the aforementioned streets was the highest in the assortment on Navoi Street, and the lowest $(4,337 \mathrm{mg} / \mathrm{g})$ was observed in the assortment grown on Amur Temur Street, due to the ability of chestnut tree adaptation to the above trees. was found to be relatively low.

It is worth noting that the chestnut tree, which grows on the streets of southern Tashkent, is the most resistant to atmospheric pollutants (after the Japanese tour). This is due to the fact that, first of all, the experiments in Tashkent have

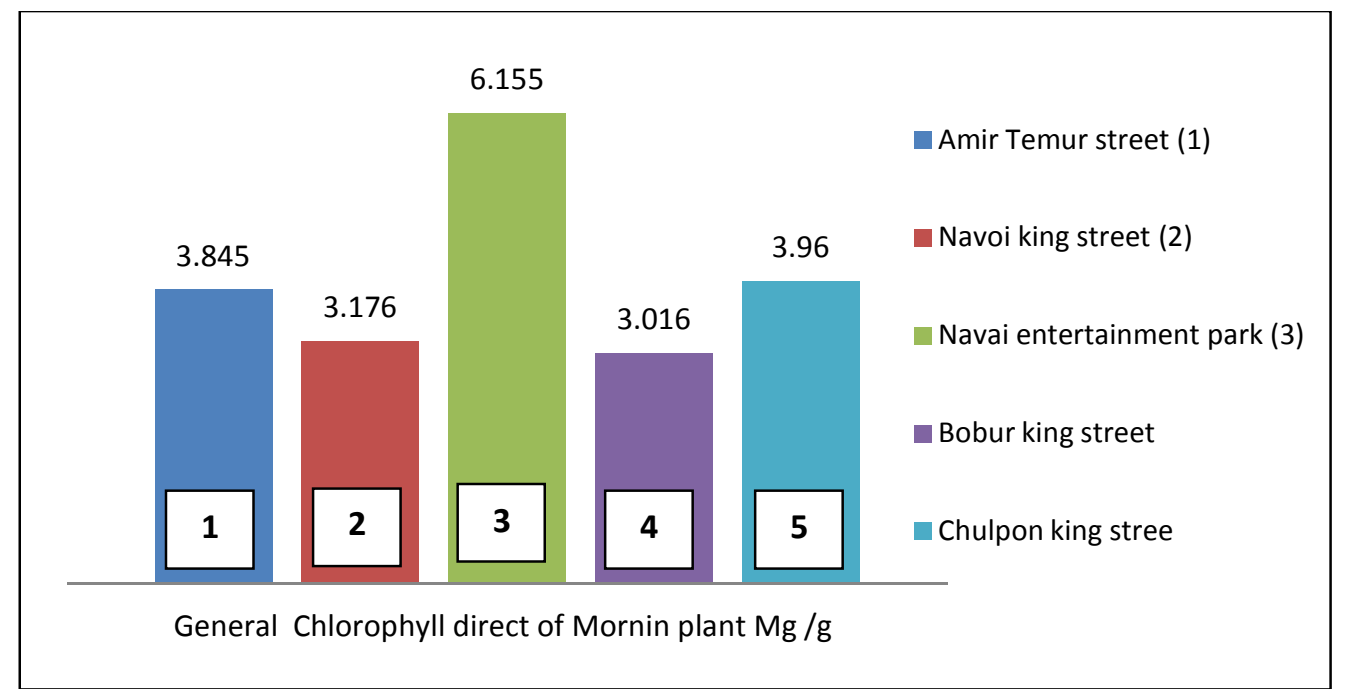

Fig. 1. Changes in the total content of chlorophyll in leaves of mornin plant along the streets (Due to solids) 


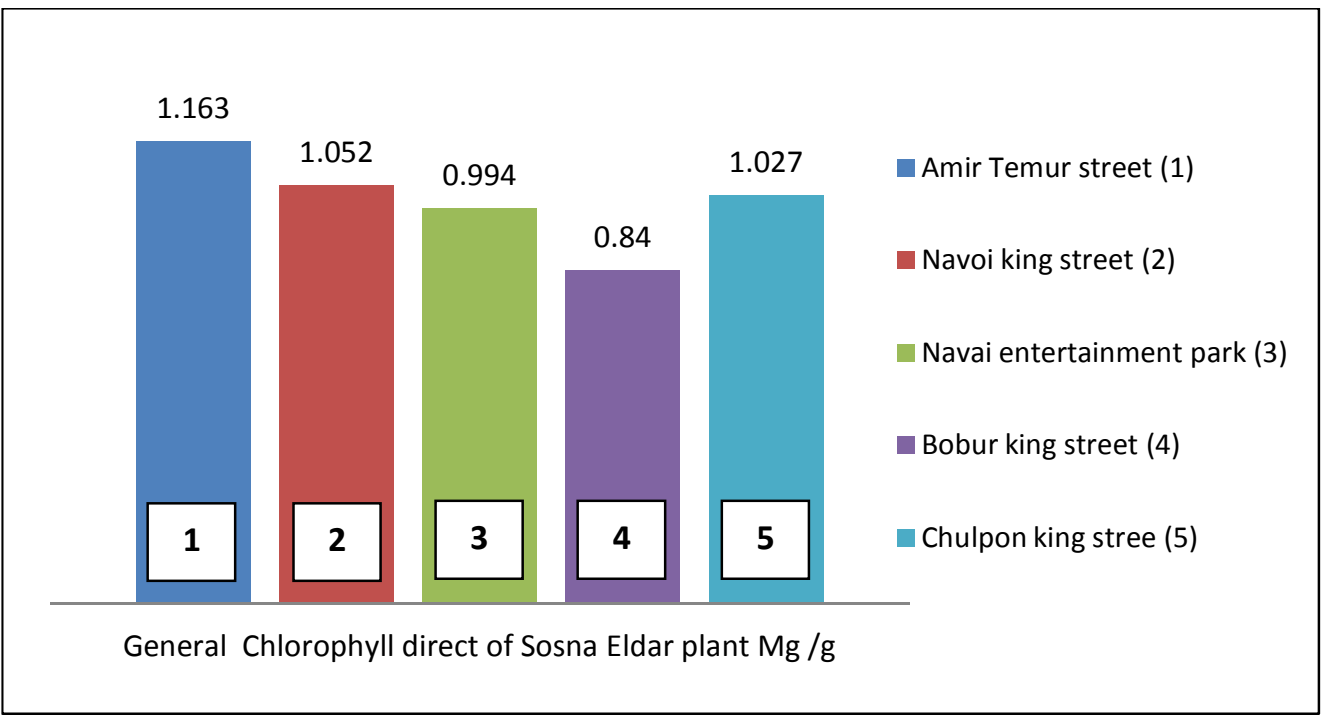

Fig. 2. Changes in the total content of chlorophyll in leaves of sosna elder plant along the streets (Due to solids)

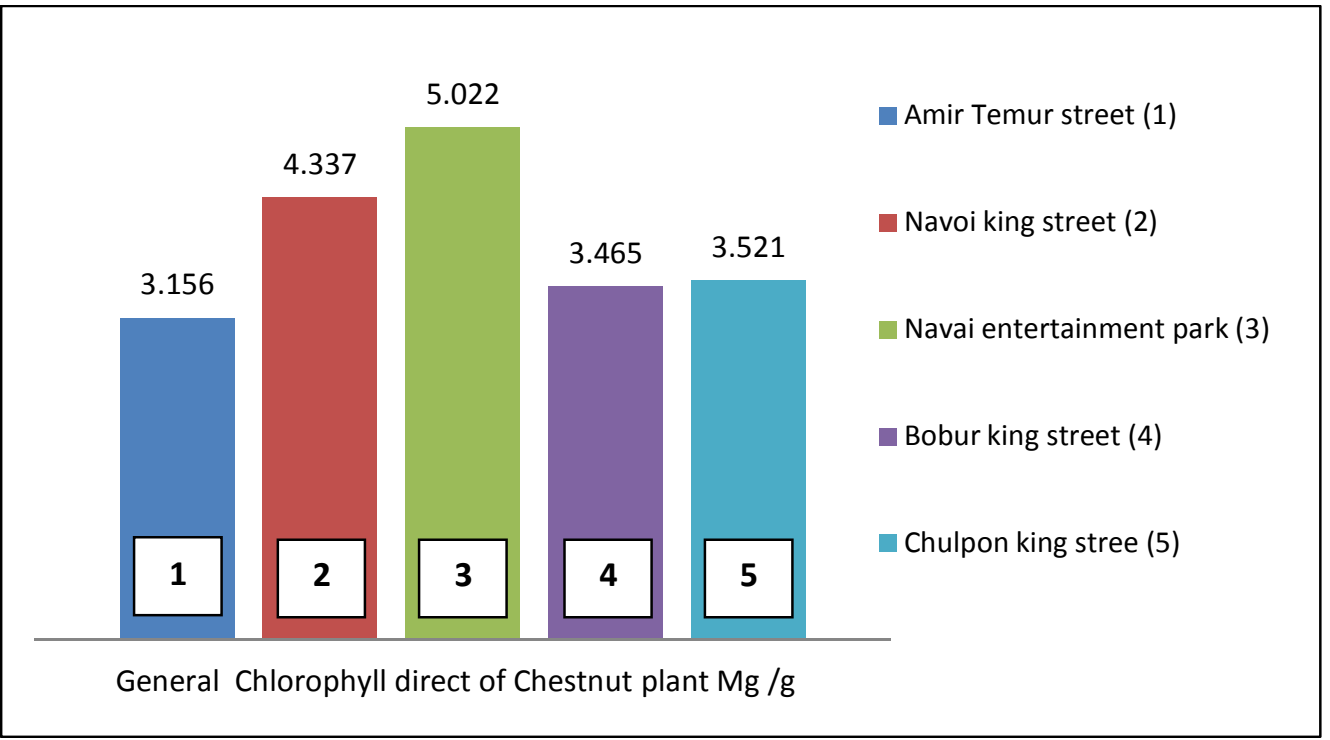

Fig. 3. Changes in the total content of chlorophyll in leaves of chestnut plant along the streets (Due to solids)

been a long time and the atmospheric air has changed and the composition of the Andijan atmospheric air is naturally contaminated.

This means that the high air pollution of Babur Avenue is high, where pigments of growing oak (dub) and fir tree leaves have a negative impact on the synthesis process. A. Temur Street had more adverse effects on the formation of pigments on the leaves of this tree due to less air pollution than other streets. In general, juniper trees are more susceptible to adverse effects, resulting in less pigmentation on the leaves, and oak (dub) is more viable, and the amount of pigments in the leaves is higher than the other pigments.

We continued these experiments, namely the seasonal variation of green pigments in leaves of these ornamental trees. The results of the experiments show that the amount of pigments in the tree leaves varies considerably compared to the season. 
The amount of pigments in the studied tree leaves varies depending on the season, and the total chlorophyll content in the selected tree leaves decreases from spring to autumn.

\section{CONCLUSION}

In the city of Andijan from the growing assortment, the results of phenological observations on oak (dub), chestnut, juniper and newly grown Pavlonian ornamental trees revealed that the trees were resistant to adverse effects. Horns taken from selected ornamental tree leaves as objects of green and yellow pigments were detected in atmospheric air. a slight decrease in the ratio of control variants (Navoi garden). Oaks (dub) increased by $40 \%$, chestnuts by $20 \%$, Navoi Street, pavilion increased by $20 \%$, fir trees increased by $18 \%$ ).

Planting decorative trees on highways improves atmospheric air. In addition, the role of ornamental trees, such as pavilions, owls, firs, plays an important role in the emission of harmful substances into the atmosphere from cars and industrial enterprises.

\section{COMPETING INTERESTS}

Authors have declared that no competing interests exist.

\section{REFERENCES}

1. Book, A Kayumov Landscaping of settlements. 2013-Tashkent. P.T. Ordinary. 1964;23-24.

2. Research Article. Urban forestry and urban gardening. 2014;13(1):94-102 Pellegrini.
3. Eroksina VI, Zherebtsova GP, Volftrub TI. Greened-populated places. Ma: Stroyizdat; 1987.

4. Belov VV Gigienik o'rmonning rolini baholash // O'rmon xo'jaligi. 1964;1:62-70.

5. Research Article. Phytotoxic effect of fluorides plant science. Robert Baroni Fornaziero. 2001;161(5):979-985.

6. Book of L. Brusso AD, Matthias AS, Comrie SA. Musil. Chapter 17: Air Pollution Ecology and the Science of Pollution. $3^{\text {rd }}$ Edition. 2019;293-309.

7. The book of Pulomi Chakravarti, Manoj Kumar Chapter 6: Micrometeorological conditions and microclimate of flower species in the restoration and increase of pollution: Book of an integrated approach Chapter (Elsevier). 2019;203-219.

8. Book of Bhanu Pandey, Krishna Kumar Chowdhary Chapter 9: Air pollution: A role in climate change and its effect on crop production. Climate Change and Agricultural Ecosystems, Chapter (Elsevier). 2019;211-247.

9. The database is protected by copyright (C) www.uz.denemetr.com 2000-2015 To copy the material, specify the link. Contact the administration

10. National report - T. Chinor ENC. 2008;287.

11. Research Article. Full text access. Combined NOx and traffic noise in Trabzon, Turkey. Science of the Total Environment. Volume 696 of December 15, 2019, Article 134044 Melike Nese Tezel, Sea Sari, Nesimi Ozkurt, S. Sinan Sharp.

12. Book TT, Tursunov TU. Rakhimova Book Ecology. 2006;74-75.

(c) 2019 Muhammatovich et al.; This is an Open Access article distributed under the terms of the Creative Commons Attribution License (http://creativecommons.org/licenses/by/4.0), which permits unrestricted use, distribution, and reproduction in any medium, provided the original work is properly cited.

Peer-review history:

The peer review history for this paper can be accessed here: https://sdiarticle4.com/review-history/52518 